\title{
Decompressive Laminectomy Alone for Degenerative Lumbar Scoliosis with Spinal Stenosis: Incidence of Post-Laminectomy Instability in the Elderly
}

\author{
Kee-Yong Ha, MD, Young-Hoon Kim, MD*, Sang-Il Kim, MD*, \\ Hyung-Youl Park, $\mathrm{MD}^{\dagger}$, Jeung-Hwan Seo, MD \\ Department of Orthopaedic Surgery, Spine Center, Kyung Hee University College of Medicine, \\ Kyung Hee University Hospital at Gangdong, Seoul, \\ ${ }^{*}$ Department of Orthopaedic Surgery, Seoul St. Mary's Hospital, College of Medicine, The Catholic University of Korea, Seoul, \\ ${ }^{\dagger}$ Department of Orthopaedic Surgery, Eunpyeong St. Mary's Hospital, College of Medicine, The Catholic University of Korea, Seoul, Korea
}

Background: Decompressive laminectomy alone for degenerative lumbar scoliosis (DLS) is not recommended because it can lead to further instability. However, it is uncertain whether instability at the decompressed segments is directly affected by laminectomy or the natural progression of DLS. The purpose of this study was to evaluate the surgical outcome of decompressive laminectomy alone for DLS with spinal stenosis and to determine whether the procedure leads to post-laminectomy instability (PLI).

Methods: We retrospectively reviewed 60 patients with DLS. They were divided into 2 groups according to PLI criteria: stable group and PLI group. The PLI group was subdivided into 2 groups based on the level of PLI: the first group that showed PLI at the index laminectomy level (PLI-I) and the second group that showed PLI at another level other than the laminectomy level (PLI-NI). Radiological evaluation was performed to determine factors associated with the progression of DLS. Pain and disability outcomes were assessed.

Results: There were 34 patients (56.7\%) in the stable group and 26 patients (43.3\%) in the PLI group. Twelve patients $(20.0 \%)$ underwent revision surgery. Eleven patients (18.3\%) showed PLI at the index segments (PLI-I group), and 15 patients (25\%) showed $\mathrm{PLI}$ at the adjacent or cephalad segments, not related to the laminectomy site (PLI-NI group). Four patients underwent revision surgery in the stable group and 8 in the PLI group. Survivorship analyses revealed that the predicted survivorship of DLS was $90.0 \%$ at 12 months and $86.4 \%$ at 24 months after laminectomy.

Conclusions: The development of PLI was not always related to laminectomy at the index level. However, PLI developed more rapidly at the index level, compared to the natural progression of the scoliotic curve at the adjacent segments.

Keywords: Lumbosacral region, Scoliosis, Spondylosis, Laminectomy, Disease progression

Received December 17, 2019; Accepted April 16, 2020

Correspondence to: Kee-Yong Ha, MD

Department of Orthopaedic Surgery, Kyung Hee University College of Medicine and Spine Center, Kyung Hee University Hospital at Gangdong, 892 Dongnam-ro, Gangdong-gu, Seoul 05278, Korea

Tel: +82-2-440-7482, Fax: +82-2-440-7485

E-mail: kyh@catholic.ac.kr
Degenerative lumbar scoliosis (DLS) is characterized by a mild curve, loss of lumbar lordosis, and instability at multiple segments. DLS presents with facet arthritis, laminar hypertrophy, and marginal osteophytosis. Resultant stenosis can produce disabling radiating pain and neurogenic claudication. ${ }^{1)}$ Therefore, the primary aim of surgery for DLS with stenotic symptoms is to relieve pain by decompression. However, surgical interventions for DLS 
Ha et al. Post-Laminectomy Instability in Degenerative Lumbar Scoliosis

Clinics in Orthopedic Surgery • Vol. 12, No. 4, $2020 \bullet$ www.ecios.org

encompass a wide spectrum ranging from decompressive laminectomy (DL) to instrumented fusion. ${ }^{1-5)}$ Thus, surgical indications for decompression alone or decompression with fusion remain unclear.

Microscopic bilateral decompression can reduce postoperative segmental instability. ${ }^{6}$ However, DL alone can result in further postoperative destabilization in patients with spine deformity. ${ }^{7,8)}$ Arthrodesis is recommended in selected patients to obtain stability and prevent the progression of deformity. Medical comorbidities should be considered when extensive long-segment fusion is performed because correction and prevention of deformity by instrumented fusion can induce surgical complications especially in the elderly. ${ }^{9}$

Therefore, the selection of a surgical method should depend on comorbidities in the elderly. We evaluated clinical and the radiological outcomes of DL alone for DLS in the elderly (PLI) to determine whether post-laminectomy instability (PLI) is affected by the procedure.

\section{METHODS}

\section{Study Design}

This retrospective study was approved by institutional review board of Seoul St. Mary's Hospital (IRB No. KC15RISI0019). The informed consent was waived. Between May 2003 and October 2011, 72 patients underwent DL alone for DLS associated with stenosis. The inclusion criteria in this study were as follows: (1) patient's age over 70 years at the time of surgery, (2) failed conservative treatment after 6 months, (3) scoliosis exceeding $10^{\circ}$ (as measured by the Cobb angle), (4) complete radiographic and clinical data with at least 2 years of follow-up. The exclusion criteria were as follows: osteoporotic compression fracture, history of previous spinal surgery, metabolic bone disease, pathologic bone disease, and preexisting idiopathic scoliosis. Each patient underwent radiographic evaluation with a regular interval. Among 72 patients, 12 (16.7\%) were lost to followup or had insufficient data. Therefore, 60 patients were included in the study (male : female, 15 : 45). Demographic data including sex, age, osteoporosis, and postoperative follow-up period were collected by medical chart review.

PLI was defined as the presence of any of the following features: (1) collapse of the intervertebral disc space with endplate sclerosis with or without a gas shadow; (2) greater than $5^{\circ}$ of coronal wedging of the disc space; (3) $>6 \mathrm{~mm}$ lateral translation; and (4) increased rotational subluxation compared with an initial scoliosis angle.

All patients were divided into 2 groups according to the PLI criteria: stable group and PLI group. The PLI group was also divided into 2 groups according to the developing level of PLI: PLI-I group showed PLI at the index level, and PLI-NI group showed PLI at the cephalad segments unrelated to the laminectomy site.

\section{Surgical Indications and Techniques}

The primary indication for DL was neurogenic claudication and no response to conservative treatment for 6 months. The decompression level was determined according to clinical symptoms along with computed tomography myelogram (CT myelogram) and magnetic resonance imaging (MRI) findings. On CT-myelograms and/or MRI, all patients had a complete block of the contrast medium in at least 1 segment. Most patients underwent laminectomy with bilateral decompression of nerve roots, including partial medial facetectomy (less than $50 \%$ of the width of the inferior articular process) in the area of major dura sac or nerve root compression. However, all patients did not undergo discectomy and resection of more than half of bilateral facetectomy. However, laminectomy was not performed in cases of an incomplete block of the contrast medium on CT myelogram and MRI without obvious clinical symptoms. Laminectomy was extended to 1 level in 32 patients, 2 levels in 24, and 3 levels in 4 . The average number of laminectomy level was $1.4 \pm 0.5$ in the stable group and $1.4 \pm 0.6$ in the PLI group.

\section{Clinical Outcome}

Pain and disability were scored by using a visual analog scale (VAS) and the Oswestry disability index (ODI), respectively. Data obtained at each follow-up included radiographic findings and VAS and ODI scores.

\section{Radiographic Outcome}

All patients underwent standing anteroposterior and dynamic lateral flexion and extension radiography of the lumbar spine. Radiological parameters included the following: (1) Scoliosis angle. (2) Lumbar lordosis from the upper endplate of L1 to the lower endplate of L5. (3) The disc index: the ratio of disc height on the decreased disc height on the opposite side. (4) Lateral osteophyte difference: the difference between the lengths of the lateral osteophytes on each side. The lengths of the lateral osteophytes are the sums of the perpendicular distance measured from the reference line to the lateral ends of the osteophytes on the upper and lower end plates. (5) Lateral listhesis: the distance from the reference line of the laterally translated vertebral body to that of the lower vertebra. (6) Each segmental angle of L2-3 and L3-4. (7) The sum of L2-3 and L3-4 segmental angles. ${ }^{10,11)}$ 
Ha et al. Post-Laminectomy Instability in Degenerative Lumbar Scoliosis

Clinics in Orthopedic Surgery • Vol. 12, No. 4, $2020 \bullet$ www.ecios.org

\section{Statistical Analysis}

The results were expressed as mean \pm standard deviation. Statistical analysis was performed using IBM SPSS ver. 21 (IBM Corp., Armonk, NY, USA). Continuous variables were analyzed by Mann-Whitney $U$-test. Chi-square tests were used to evaluate nominal data. Spearman correlation analyses were performed to determine the relationship between radiologic parameters and clinical parameters. A $p$-value $<0.05$ was considered statistically significant. Sur-

\section{Table 1. Demographics of the Patients}

\begin{tabular}{lccc}
\multicolumn{1}{c}{ Variable } & Stable group $(\mathrm{n}=34) \mathrm{PLI}$ group $(\mathrm{n}=26)$ & $p$-value \\
\hline Age $(\mathrm{yr})$ & $76.9 \pm 9.3$ & $76.4 \pm 6.8$ & 0.503 \\
Sex $(\mathrm{M}: \mathrm{F})$ & $7: 27$ & $8: 18$ & $0.367^{*}$ \\
\hline Follow-up (mo) & $43.2 \pm 38.3$ & $28.1 \pm 31.5$ & 0.109 \\
BMD (T-score) & $-1.9 \pm 1.3$ & $-2.5 \pm 0.9$ & 0.107 \\
$\begin{array}{c}\text { Number of laminec- } \\
\text { tomy level }\end{array}$ & $1.4 \pm 0.5$ & $1.4 \pm 0.6$ & 0.783 \\
\hline
\end{tabular}

$\overline{\text { Values are presented as mean } \pm \text { standard deviation. Statistical significan- }}$ ce was tested by Mann-Whitney U-test.

PLI: post-laminectomy instability, BMD: bone mineral density.

${ }^{*}$ Statistical results of chi-square tests. vivorship analysis was performed in accordance with the recommendations of Kaplan and Meier. The end point for failure was defined as a revision surgery.

\section{RESULTS}

\section{Demographics of the Patients}

Thirty-four (56.7\%) patients were included in the stable group and 26 (43.3\%) in the PLI group (Table 1). Eleven of the 60 patients $(18.3 \%)$ belonged to the PLI-I group (PLI at the index level) (Fig. 1), and 15 (25\%) to the PLI-NI group (PLI at the segments unrelated to the laminectomy site) (Fig. 2). Twelve $(20.0 \%)$ patients underwent revision surgery (Table 2): 4 patients in the stable group and 8 patients in the PLI group, but the difference between groups was not statistically significant $(p=0.068)$. In the subgroup analysis, 4 patients in the PLI-I group and PLI-NI group each underwent revision surgery.

\section{Patient Age}

The average age of patients was $76.9 \pm 9.3$ years in the stable group and $76.4 \pm 6.8$ years in the PLI group $(p=0.503)$ (Table 1). The mean final scoliosis angle was $22.1^{\circ} \pm 14.9^{\circ}$ in patients $\geq 75$ years of age (82.1 \pm 5.1 years), whereas it
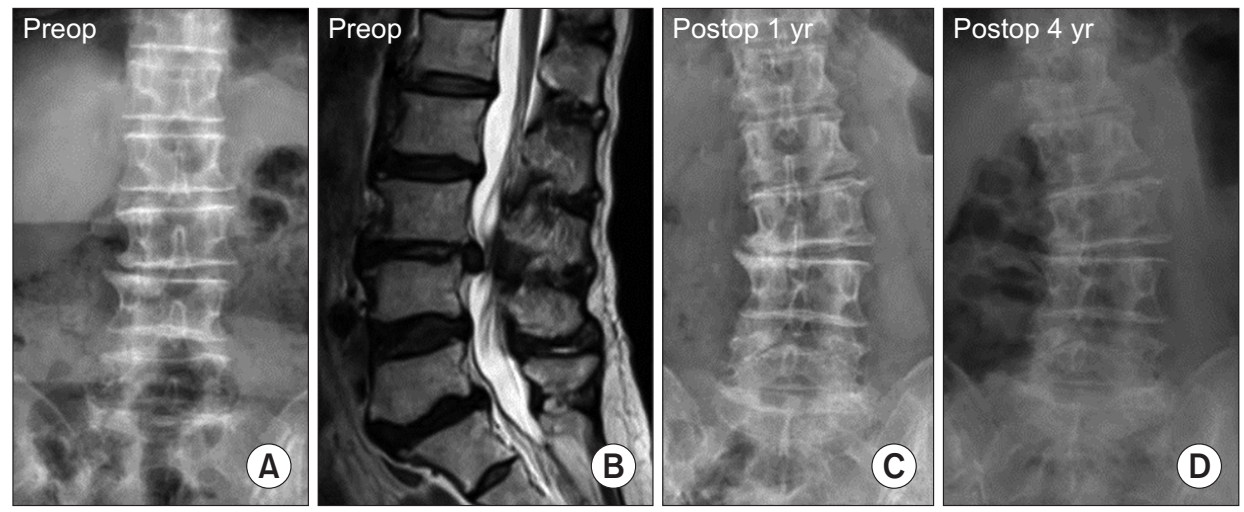

Fig. 1. A 78-year-old patient underwent decompressive laminectomy at L3-4. She had post-laminectomy instability at the index laminectomy level. $(A, B)$ Preoperative (Preop) $\mathrm{X}$-ray and magnetic resonance imaging. $(C, D)$ Postoperative (Postop) $\mathrm{X}$-rays showing deterioration of the scoliotic curvature with collapse of the intervertebral disc space at $L 3-4$.
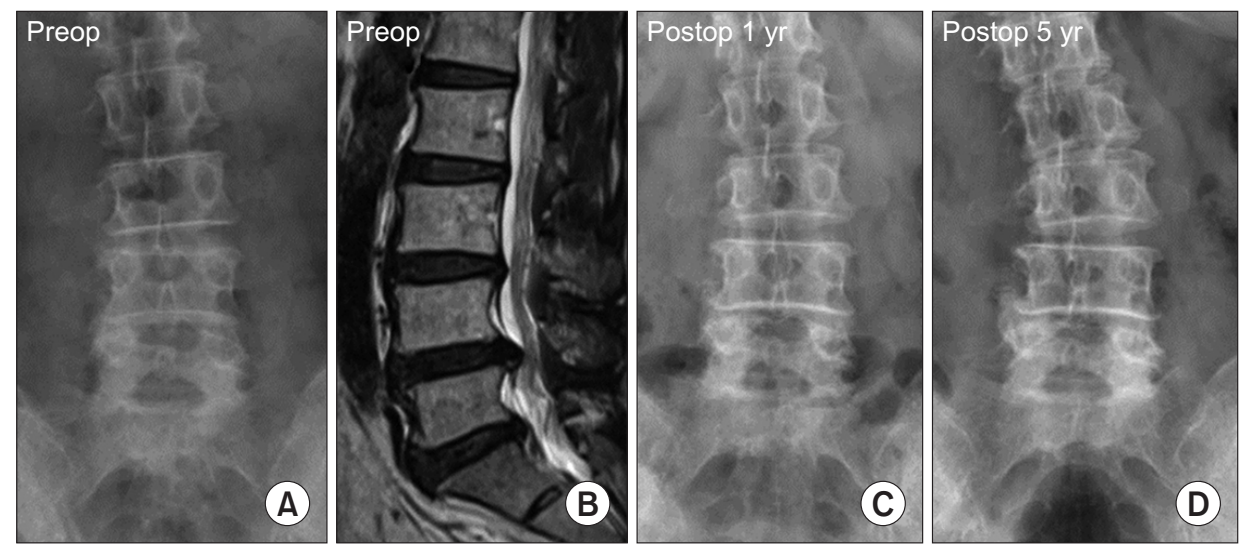

Fig. 2. A 76-year-old patient underwent decompressive laminectomy. She had post-laminectomy instability at another level other than the laminectomy level. $(A, B)$ Preoperative (Preop) X-ray and magnetic resonance imaging. $(C, D)$ Postoperative (Postop) $X$-rays showing deterioration of the scoliotic curvature. 
Ha et al. Post-Laminectomy Instability in Degenerative Lumbar Scoliosis

Clinics in Orthopedic Surgery • Vol. 12, No. 4, $2020 \bullet$ www.ecios.org

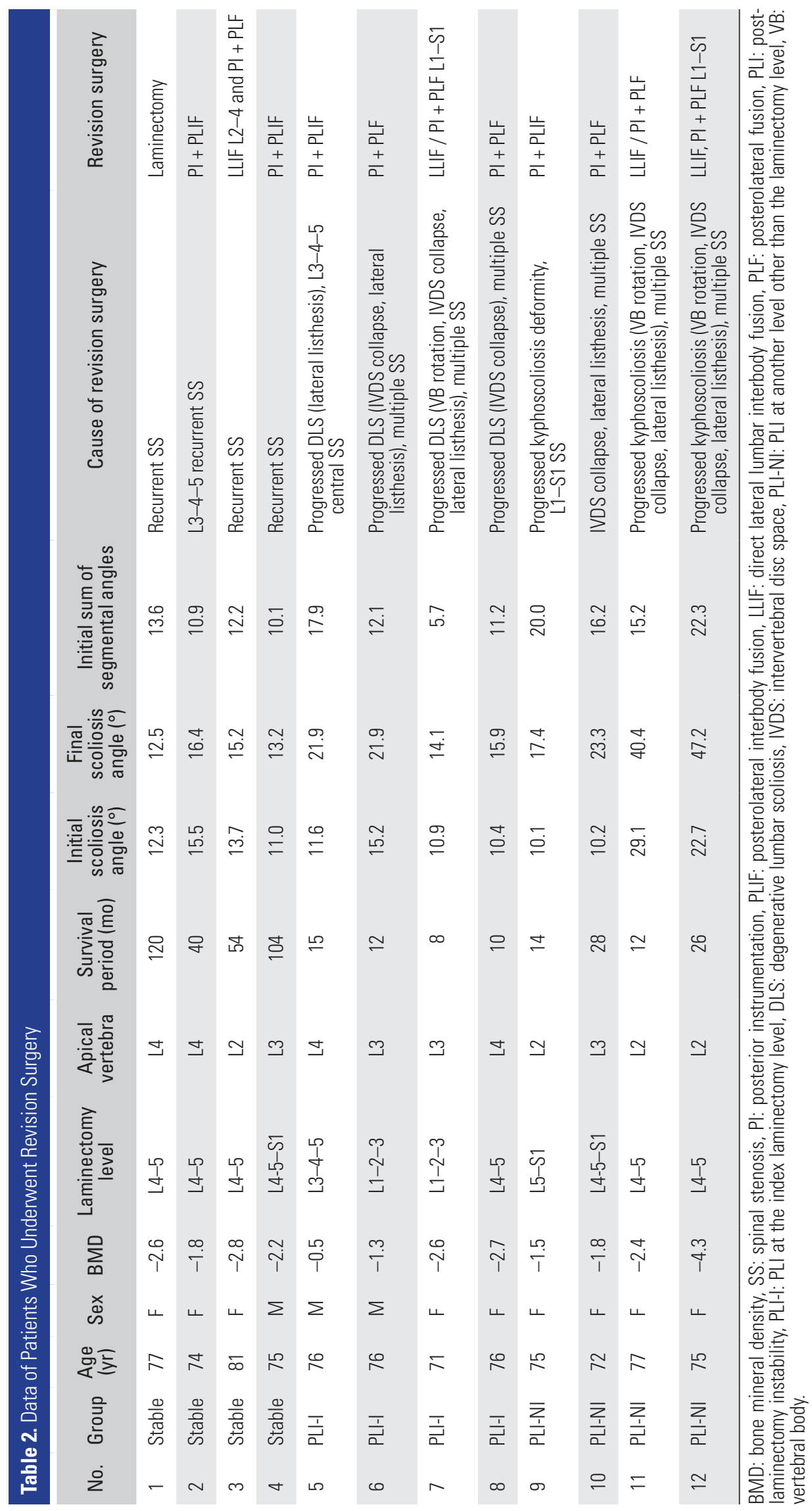


Ha et al. Post-Laminectomy Instability in Degenerative Lumbar Scoliosis

Clinics in Orthopedic Surgery • Vol. 12, No. 4, $2020 \bullet$ www.ecios.org

was $16.9^{\circ} \pm 6.0^{\circ}$ in patients $<75$ years of age $(68.6 \pm 5.3$ years) ( $p=0.548)$. However, $\geq 75$ years of age was not associated with the progression of DLS (odds ratio, 1.12; 95\% confidence interval [CI], 0.39-3.18).

\section{Osteoporosis}

The mean bone mineral density (BMD) of all patients was $-2.2 \pm 1.1 ; 32$ patients had osteoporosis and 28 patients did not. There was a statistically significant correlation between the progression of DLS and BMD (odds ratio, 3.21; 95\% CI, 1.10-9.44). The difference between the stable group and PLI group was not statistically significant $(-1.9 \pm 1.3$ vs. $-2.5 \pm 0.9, p=0.107$ ) (Table 1$)$.

\section{Radiological Outcomes \\ Cobb angle}

There was no statistically significant difference in the initial Cobb angle between the stable group and PLI group $\left(15.2^{\circ} \pm 8.1^{\circ}\right.$ vs. $\left.15.3^{\circ} \pm 6.8^{\circ} ; p=0.698\right)$; the angle at the last follow-up was $16.1^{\circ} \pm 7.7^{\circ}$ and $23.8^{\circ} \pm 15.1^{\circ}$, respectively, and the difference was statistically significant $(p=$ 0.014) (Table 3). The preoperative angle was not statistically significantly different between the PLI-I group and PLI-NI group $\left(15.3^{\circ} \pm 9.3^{\circ}\right.$ vs. $\left.15.4^{\circ} \pm 4.6^{\circ}, p=0.259\right)$; there was no statistically significant difference between the 2 groups at the last follow-up $\left(25.1^{\circ} \pm 9.8^{\circ}\right.$ vs. $22.8^{\circ} \pm 9.7^{\circ}$, $p=0.305)$ (Table 4).

\section{Lumbar Lordosis}

The mean lumbar lordosis was $22.6^{\circ} \pm 15.0^{\circ}$ preoperatively and $25.1^{\circ} \pm 13.5^{\circ}$ at the last follow-up. However, there was no statistically significant difference between the stable and PLI groups (initial, $p=0.244$; final, $p=0.765$ ) (Table 3). On the subgroup analysis of the PLI group, the preoperative lordosis was statistically significantly different between the PLI-I group and PLI-NI group $\left(33.8^{\circ} \pm 10.3^{\circ}\right.$ vs. $11.6^{\circ} \pm$ $\left.13.9^{\circ}, p=0.001\right)$. A statistically significant difference was found between the 2 groups at the last follow-up (36.1 \pm $19.7^{\circ}$ vs. $\left.19.7^{\circ} \pm 12.3^{\circ}, p=0.024\right)$ (Table 4$)$.

\section{Disc Index}

The disc index at L3 was similar between the stable group and PLI group on the initial $(0.81 \pm 0.13$ vs. $0.73 \pm 0.20$, $p=0.149)$ and final radiographs $(0.67 \pm 0.19$ vs. $0.70 \pm$ $0.20, p=0.521)$. The index at L4 was similar between the stable group and PLI group on the initial $(0.76 \pm 0.07$ vs. $0.72 \pm 0.17, p=0.218)$ and final radiographs $(0.74 \pm 0.11$ vs. $0.73 \pm 0.15, p=0.920$ ) (Table 3 ). In addition, here was no statistically significant difference between the PLI-I group and PLI-NI group in the initial disc index at L3 and
L4. However, the final disc index was statistically significantly lower in the PLI-NI group than in the PLI-I group $(0.85 \pm 0.18$ vs. $0.59 \pm 0.14, p=0.002)$ (Table 4$)$.

\section{Lateral Osteophyte}

The initial lateral osteophyte was $6.1 \pm 5.9 \mathrm{~mm}$ in the stable group and $7.8 \pm 8.7 \mathrm{~mm}$ in the PLI group, but there was no statistically significant difference $(p=0.536)$ (Table $3)$. Initial and final lateral osteophytes were similar between the PLI-I group and PLI-NI group (initial, $9.2 \pm$ $11.6 \mathrm{~mm}$ vs. $6.8 \pm 5.9 \mathrm{~mm}, p=0.574$; finial, $5.8 \pm 10.46$ $\mathrm{mm}$ vs. $10.8 \pm 12.1 \mathrm{~mm}, p=0.134$ ) (Table 4 ).

\section{Lateral Listhesis}

The lateral listhesis on the initial radiograph was at least $6 \mathrm{~mm}$ in 17 patients (28.3\%), whereas 43 had a lateral listhesis of $<6 \mathrm{~mm}$ or no listhesis; the initial scoliosis angle was $21.0^{\circ} \pm 10.3^{\circ}$ and $12.9^{\circ} \pm 4.7^{\circ}$, respectively $(p<0.001)$. On the final radiographs, 23 patients had a lateral listhesis of $>6 \mathrm{~mm}$, whereas 37 had a lateral listhesis of $<6 \mathrm{~mm}$; the final scoliosis angle was $22.3^{\circ} \pm 8.2^{\circ}$ and $17.6^{\circ} \pm 13.6^{\circ}$, respectively $(p=0.001)$. The progression of DLS was associated with a lateral listhesis of $>6 \mathrm{~mm}$ on the final radiograph (odds ratio, 4.43; 95\% CI, 1.46-13.45), but there was no significant association with the initial lateral listhesis of $>6 \mathrm{~mm}$ (odds ratio, 1.72 ; 95\% CI, 0.56-5.34).

The initial lateral listhesis was similar between the stable group and PLI group $(4.8 \pm 2.4 \mathrm{~mm}$ vs. $4.9 \pm 2.9$ $\mathrm{mm}$ ). However, at the last follow-up, the PLI group showed more progression than the stable group $(7.0 \pm 2.6 \mathrm{~mm}$ vs. $4.5 \pm 3.0 \mathrm{~mm}, p=0.001$ ) (Table 3 ). In the subgroup analysis of the PLI group, the preoperative lateral listhesis was not statistically significantly different between the PLI-I group and PLI-NI group ( $5.0 \pm 3.5$ vs. $4.9 \pm 2.5, p=0.856$ ), and there was no statistically significant difference between the 2 groups at the last follow-up $(7.3 \pm 3.4$ vs. $6.8 \pm 1.8$, $p=0.938)$ (Table 4).

\section{Segmental Angle}

There were no statistically significant difference in the initial segmental angle between the stable and PLI groups (L2-3, $p=0.215$ and L3-4, $p=0.403$ ) or in the final segmental angle (L2-3, $p=0.687$ and L3-4, $p=0.179$ ) (Table 3 ). The mean of the sum of the L2-3 and L3-4 segmental angles was $10.7^{\circ} \pm 6.5^{\circ}$ preoperatively and $10.7^{\circ} \pm 6.0^{\circ}$ at the last follow-up. Differences between the 2 groups were not statistically significant (initial, $p=0.197$; final, $p=$ 0.162 ). When we divided the patients into 3 groups based on the sum of the L2-3 and L3-4 segmental angles, ${ }^{10)}$ a greater proportion of patients with an increase in the angle 
Ha et al. Post-Laminectomy Instability in Degenerative Lumbar Scoliosis

Clinics in Orthopedic Surgery • Vol. 12, No. 4, $2020 \bullet$ www.ecios.org

Table 3. Radiological and Clinical Parameters between Stable Group and PLI Group

\begin{tabular}{|c|c|c|c|c|}
\hline Variable & Time & Stable group $A(n=34)$ & PLI group $(n=26)$ & $p$-value \\
\hline \multicolumn{5}{|l|}{ Radiological outcome } \\
\hline \multirow[t]{2}{*}{ Scoliosis angle $\left({ }^{\circ}\right)$} & Initial & $15.2 \pm 8.1$ & $15.3 \pm 6.8$ & 0.698 \\
\hline & Final & $16.1 \pm 7.7$ & $23.8 \pm 15.1$ & $0.014^{*}$ \\
\hline \multirow[t]{2}{*}{ Lordosis $\left({ }^{\circ}\right)$} & Initial & $23.8 \pm 13.8$ & $20.9 \pm 16.6$ & 0.244 \\
\hline & Final & $24.0 \pm 10.7$ & $26.7 \pm 16.7$ & 0.765 \\
\hline \multirow[t]{2}{*}{ L2-3 segmental angle $\left(^{\circ}\right)$} & Initial & $6.1 \pm 5.0$ & $5.8 \pm 2.9$ & 0.215 \\
\hline & Final & $5.8 \pm 4.8$ & $5.6 \pm 4.1$ & 0.687 \\
\hline \multirow[t]{2}{*}{ L3-4 segmental angle $\left(^{\circ}\right)$} & Initial & $4.3 \pm 3.4$ & $4.9 \pm 3.5$ & 0.403 \\
\hline & Final & $4.9 \pm 3.4$ & $6.8 \pm 4.6$ & 0.179 \\
\hline \multirow[t]{2}{*}{ Sum of segmental angles $\left({ }^{\circ}\right)$} & Initial & $10.7 \pm 6.5$ & $12.3 \pm 5.1$ & 0.197 \\
\hline & Final & $10.7 \pm 6.0$ & $12.9 \pm 5.9$ & 0.162 \\
\hline \multirow[t]{2}{*}{ Distance from CSVL (mm) } & Initial & $35.0 \pm 11.9$ & $37.6 \pm 8.9$ & 0.280 \\
\hline & Final & $37.2 \pm 9.4$ & $37.8 \pm 14.7$ & 0.909 \\
\hline \multirow[t]{2}{*}{ Disc index L-3 } & Initial & $0.81 \pm 0.13$ & $0.73 \pm 0.20$ & 0.149 \\
\hline & Final & $0.67 \pm 0.19$ & $0.70 \pm 0.20$ & 0.521 \\
\hline \multirow[t]{2}{*}{ Disc index L-4 } & Initial & $0.76 \pm 0.07$ & $0.72 \pm 0.12$ & 0.218 \\
\hline & Final & $0.74 \pm 0.11$ & $0.73 \pm 0.15$ & 0.920 \\
\hline \multirow[t]{2}{*}{ Lateral osteophyte difference (mm) } & Initial & $6.1 \pm 5.9$ & $7.8 \pm 8.7$ & 0.536 \\
\hline & Final & $6.3 \pm 6.5$ & $8.7 \pm 11.6$ & 0.862 \\
\hline \multirow[t]{2}{*}{ Lateral listhesis } & Initial & $4.8 \pm 2.4$ & $4.9 \pm 2.9$ & 0.781 \\
\hline & Final & $4.5 \pm 3.0$ & $7.0 \pm 2.6$ & $0.001^{*}$ \\
\hline \multicolumn{5}{|l|}{ Clinical outcome } \\
\hline \multirow[t]{2}{*}{ ODI } & Initial & $48.0 \pm 8.9$ & $52.1 \pm 9.5$ & 0.309 \\
\hline & Final & $42.1 \pm 15.6$ & $40.4 \pm 14.9$ & 0.199 \\
\hline \multirow[t]{2}{*}{ Back VAS } & Initial & $6.7 \pm 2.1$ & $7.3 \pm 1.6$ & 0.174 \\
\hline & Final & $4.8 \pm 2.0$ & $5.2 \pm 1.5$ & 0.301 \\
\hline \multirow[t]{2}{*}{ Leg VAS } & Initial & $6.7 \pm 2.1$ & $5.6 \pm 2.4$ & 0.342 \\
\hline & Final & $5.6 \pm 2.4$ & $6.4 \pm 2.5$ & 0.189 \\
\hline
\end{tabular}

Values are presented as mean \pm standard deviation.

PLI: post-laminectomy instability, CSVL: central sacral vertical line, ODI: Oswestry disability index, VAS: visual analog scale.

*Mann-Whitney $U$-test, $p<0.05$ was significant.

had the progression of DLS (linear-by-linear association, $p=0.024)$. The preoperative L2-3 segmental angle was statistically significantly different between the PLI-I group and PLI-NI group $\left(4.1^{\circ} \pm 1.8^{\circ}\right.$ vs. $\left.7.1^{\circ} \pm 2.9^{\circ}, p=0.010\right)$ and L3-4 segmental angle was not statistically significantly different $(p=0.815)$. However, a significant difference in the L3-4 segmental angle was found between the groups at the last follow-up $\left(4.5^{\circ} \pm 2.0^{\circ}\right.$ vs. $\left.8.4^{\circ} \pm 5.3^{\circ}, p=0.024\right)$ (Table 4). 
Ha et al. Post-Laminectomy Instability in Degenerative Lumbar Scoliosis

Clinics in Orthopedic Surgery • Vol. 12, No. 4, $2020 \bullet$ www.ecios.org

Table 4. Radiological and Clinical Parameters between Progression at the Level of Laminectomy (PLI-I) and at the Adjacent Level (PLI-NI)

\begin{tabular}{|c|c|c|c|c|}
\hline Variable & Time & Group PLI-I ( $n=11)$ & Group PLI-NI $(n=15)$ & $p$-value \\
\hline \multicolumn{5}{|l|}{ Radiological outcome } \\
\hline \multirow[t]{2}{*}{ Scoliosis angle $\left({ }^{\circ}\right)$} & Initial & $15.3 \pm 9.3$ & $15.4 \pm 4.6$ & 0.259 \\
\hline & Final & $25.1 \pm 20.8$ & $22.8 \pm 9.7$ & 0.305 \\
\hline \multirow[t]{2}{*}{ Lordosis $\left({ }^{\circ}\right)$} & Initial & $33.8 \pm 10.3$ & $11.6 \pm 13.9$ & $0.001^{*}$ \\
\hline & Final & $36.1 \pm 19.7$ & $19.7 \pm 12.3$ & $0.024^{*}$ \\
\hline \multirow[t]{2}{*}{ L2-3 segmental angle $\left({ }^{\circ}\right)$} & Initial & $4.1 \pm 1.8$ & $7.1 \pm 2.9$ & $0.010^{*}$ \\
\hline & Final & $4.6 \pm 2.4$ & $6.4 \pm 4.9$ & 0.335 \\
\hline \multirow[t]{2}{*}{ L3-4 segmental angle $\left({ }^{\circ}\right)$} & Initial & $4.8 \pm 3.9$ & $4.9 \pm 3.4$ & 0.815 \\
\hline & Final & $4.5 \pm 2.0$ & $8.4 \pm 5.3$ & $0.024^{*}$ \\
\hline \multirow[t]{2}{*}{ Sum of segmental angles $\left({ }^{\circ}\right)$} & Initial & $11.3 \pm 4.4$ & $13.0 \pm 5.5$ & 0.610 \\
\hline & Final & $9.1 \pm 2.3$ & $15.6 \pm 6.3$ & $0.024^{*}$ \\
\hline \multirow[t]{2}{*}{ Distance from CSVL (mm) } & Initial & $36.0 \pm 8.8$ & $38.6 \pm 9.0$ & 0.217 \\
\hline & Final & $37.2 \pm 9.4$ & $37.8 \pm 14.7$ & 0.474 \\
\hline \multirow[t]{2}{*}{ Disc index L-3 } & Initial & $0.78 \pm 0.20$ & $0.70 \pm 0.20$ & 0.443 \\
\hline & Final & $0.85 \pm 0.18$ & $0.59 \pm 0.14$ & $0.002^{*}$ \\
\hline \multirow[t]{2}{*}{ Disc index $L-4$} & Initial & $0.73 \pm 0.11$ & $0.71 \pm 0.12$ & 0.838 \\
\hline & Final & $0.77 \pm 0.96$ & $0.71 \pm 0.18$ & 0.259 \\
\hline \multirow[t]{2}{*}{ Lateral osteophyte difference (mm) } & Initial & $9.2 \pm 11.6$ & $6.8 \pm 5.9$ & 0.574 \\
\hline & Final & $5.8 \pm 10.6$ & $10.8 \pm 12.1$ & 0.134 \\
\hline \multirow[t]{2}{*}{ Lateral listhesis } & Initial & $5.0 \pm 3.5$ & $4.9 \pm 2.5$ & 0.856 \\
\hline & Final & $7.3 \pm 3.4$ & $6.8 \pm 1.8$ & 0.938 \\
\hline \multicolumn{5}{|l|}{ Clinical outcome } \\
\hline \multirow[t]{2}{*}{ ODI } & Initial & $51.1 \pm 11.1$ & $52.8 \pm 8.4$ & 0.330 \\
\hline & Final & $31.8 \pm 12.4$ & $46.6 \pm 13.6$ & $0.024^{*}$ \\
\hline \multirow[t]{2}{*}{ Back VAS } & Initial & $6.6 \pm 2.1$ & $7.0 \pm 1.3$ & 0.305 \\
\hline & Final & $4.5 \pm 1.9$ & $5.8 \pm 1.0$ & $0.008^{*}$ \\
\hline \multirow[t]{2}{*}{ Leg VAS } & Initial & $6.9 \pm 2.1$ & $7.6 \pm 1.1$ & 0.610 \\
\hline & Final & $5.5 \pm 1.9$ & $7.1 \pm 2.6$ & 0.148 \\
\hline
\end{tabular}

Values are presented as mean \pm standard deviation.

PLI: post-laminectomy instability, CSVL: central sacral vertical line, ODI: Oswestry disability index, VAS: visual analog scale.

*Mann-Whitney $U$-test, $p<0$.05 was significant.

\section{Clinical Outcomes}

Although the preoperative back VAS was lower in the stable group than in the PLI group ( $6.7 \pm 2.1$ vs. $7.3 \pm 1.6)$, it was not statistically significantly different $(p=0.174)$. Furthermore, ODI, back VAS, and leg VAS at the last follow- up were not statistically significantly different $(p=0.199$, $p=0.301$, and $p=0.189$, respectively) (Table 3 ).

The preoperative ODI was not statistically significantly different between the PLI-I group and PLI-NI group $(51.1 \pm 11.1$ vs. $52.8 \pm 8.4, p=0.330)$ (Table 4$)$; however, 
Ha et al. Post-Laminectomy Instability in Degenerative Lumbar Scoliosis

Clinics in Orthopedic Surgery • Vol. 12, No. 4, $2020 \bullet$ www.ecios.org

ODI at the last follow-up showed statistically significant difference ( $31.8 \pm 12.4$ vs. $46.7 \pm 13.6, p=0.024)$. The preoperative back VAS was not statistically significantly different between the PLI-I group and PLI-NI group (6.6 \pm 2.1 vs. $7.0 \pm 1.4, p=0.305)$. However, VAS at the last followup was significantly higher in the PLI-NI group than in the PLI-I group ( $4.5 \pm 1.9$ vs. $5.8 \pm 1.0, p=0.008)$. The preoperative leg VAS was not statistically significantly different between the PLI-I group and PLI-NI group $(6.9 \pm 2.1$ vs. $7.06 \pm 1.1, p=0.610$ ). The leg VAS at the last follow-up was higher in the PLI-NI group than in the PLI-I group without a statistical significance $(5.5 \pm 1.9$ vs. $7.81 \pm 2.6$, $p=0.148)$ (Table 4).

\section{Survivorship}

Kaplan-Meier survival analysis revealed a 1-year revisionfree rate of $90.0 \%$, a 2 -year survival rate of $86.4 \%$, and a 4 -year survival rate of $81.1 \%$ (Fig. $3 \mathrm{~A}$ ). The mean revisionfree period was $96.0 \pm 6.8$ months (95\% CI, 82.631109.374) and the median revision-free period was $104.0 \pm$ 35.5 months (95\% CI, 34.402-173.598). The log-rank test showed a statistically significant difference between the stable group and PLI group ( $88.2 \%$ vs. $69.2 \%, p=0.034)$ (Fig. 3B). Also, there was a significant difference between the PLI-I group and PLI-NI group (63.6\% vs. $86.7 \%, p=$ 0.034).

\section{DISCUSSION}

Most DLS shows instability including rotatory or translational instability or both at the involved segments. Thus, decompression alone may destabilize the involved

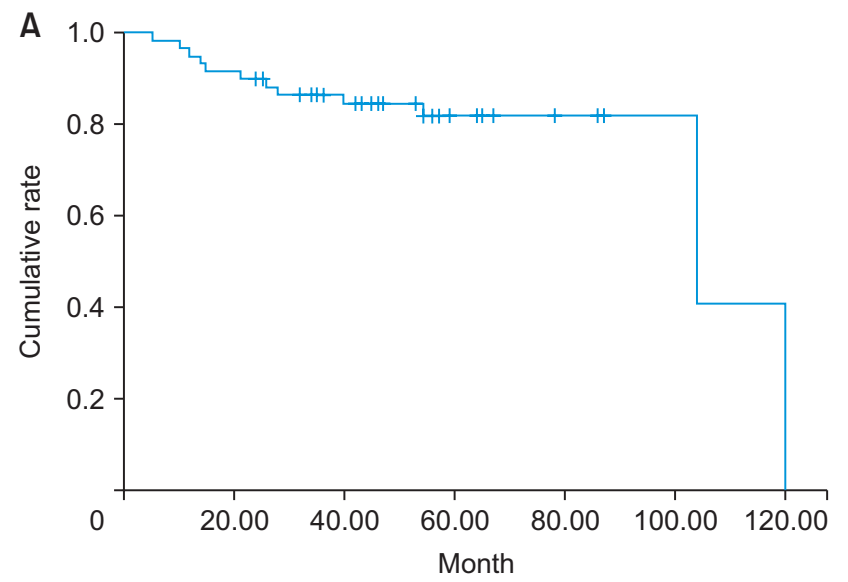

segments or accelerate instability even with attempts to preserve the integrity of the posterior ligament complex and bilateral facet joints. On the risk of instability following decompressive surgery for spinal stenosis, Schulitz ${ }^{12)}$ postulated that the main cause of instability after surgery is based on the natural history of the disease and does not originate from the extent of surgery.

However, the natural progression of DLS after DL is overlooked even though many literatures reported further progression of the deformity after DL. Hence, understanding that PLI is caused by the natural progression of the deformity or aggravation of the instability by DL could be helpful in determining the surgical extent and methods, especially for elderly patients with serious medical comorbidities. Therefore, the purpose of this study was to investigate whether the causes of PLI are directly related to surgical decompression or the natural progression of DLS.

Patients with significant osteophytes and a curve $<20^{\circ}$ had good results by decompression alone, as a surgical procedure for DLS ${ }^{3,13)} \mathrm{DL}$ would be most appropriate in patients with severe stenosis without major coronal or sagittal imbalance. ${ }^{3)}$ However, decompression may lead to a further collapse of the degenerative curve, resulting in increased instability. ${ }^{7,14,15)}$ In this study, the mean preoperative Cobb angles of the stable group and PLI group were $<20^{\circ}$. However, the coronal deformity progressed in some patients $\left(15.3^{\circ} \pm 6.8^{\circ}\right.$ to $23.8^{\circ} \pm 15.1^{\circ}$ in the PLI group).

Simmons reported that DL is not recommended due to resultant aggravation of instability, particularly in the apex of the curvature. ${ }^{16)}$ On the contrary, PLI may not be correlated with laminectomy if it is not performed at the apex of the curvature, because the apical vertebra or disc

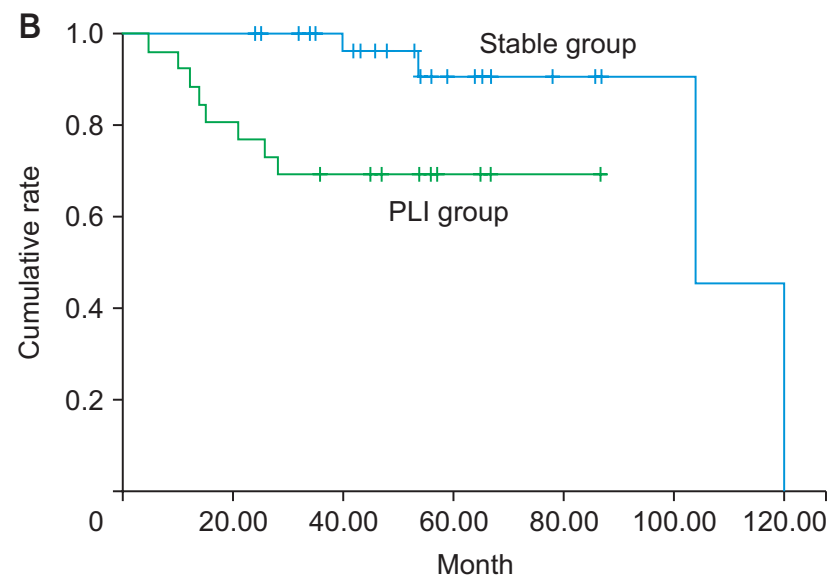

Fig. 3. (A) Kaplan-Meier survival curve of patients with revision surgery. Kaplan-Meier survivorship analysis revealed a 1-year revision-free rate of $90.0 \%$, a 2-year survival rate of $86.4 \%$, and a 4-year survival rate of $81.1 \%$. (B) Survivorship of the post-laminectomy instability (PLI) group (69.2\%) was lower than that of the stable group $(88.2 \%)$, and the log-rank test revealed that the difference between the groups was statistically significant $(p=$ 0.034). 
Ha et al. Post-Laminectomy Instability in Degenerative Lumbar Scoliosis

Clinics in Orthopedic Surgery • Vol. 12, No. 4, $2020 \bullet$ www.ecios.org

has the potential of progression of the curvature. ${ }^{10)}$ On the subgroup analysis between the PLI-I and PLI-NI groups, there were no significant differences in the final Cobb angles as well as the initial angles.

In this study, PLI was directly related to the index level only in 11 patients (18.3\%). Among 8 patients undergoing revision surgery in the PLI group, 4 patients in the PLI-I group (PLI at the index level) showed rapid progression of PLI at an average of 11.3 months (range, 8-15 months) postoperatively, compared to the PLI-NI group (PLI at the segments unrelated to the laminectomy site) that developed PLI at an average of 20.0 months (range, 12-28 months) postoperatively. Therefore, it appears that DL could aggravate PLI with or without the concurrent natural progression of deformity.

Among 34 patients in the stable group, 4 patients (11.8\%) underwent revision surgery. The cause of revision surgery in the stable group was recurrent spinal stenosis without PLI. However, the incidence of recurrent stenosis after DL is reported to range from $2.7 \%$ to $17 \%$, which is similar to the incidence of revision in our study. ${ }^{17,18)}$

All patients undergoing revision surgery in the PLI group showed significant progression of deformity, showing severe collapse of the intervertebral disc space with lateral listhesis and rotational deformity at the index level or adjacent segments. This progression of deformity might have resulted in recurrent stenotic conditions, leading to an increased need for revision surgery with the proximity of statistical significance $(p=0.068)$. However, the degree of scoliotic curve progression was unrelated to clinical outcomes. The reason is that severe collapse of the intervertebral disc space developed without increasing Cobb angle due to the compensatory curve at the adjacent segments or vertical collapse of the intervertebral disc space without an increasing scoliotic curvature.

In our study, the most important preoperative factor in determining the curve progression in the PLI group was the segmental angles of L2-3 and L3-4. Seo et al. ${ }^{10)}$ reported that the sum of segmental angles of L2-3 and L3-4 with $>10^{\circ}$ was a risk factor for natural progression of DLS. Therefore, if segmental angles of L2-3 and L3 -4 are $>10^{\circ}$, curve progression after surgery could be possible irrespective of whether natural or laminectomy-related. This study also showed a similar result to the previous study. ${ }^{10)} \mathrm{On}$ the subgroup analysis with the 3 groups, there was a significant correlation between the progression of DLS and the increase of the L2-3 and L3-4 segmental angles.

There are some limitations of this study. First this is a retrospective study with a small sample size. However, it demonstrated that the deformity progressed by either natural history of DLS or destabilization after decompression surgery. Second, the postoperative follow-up period was relatively short; the natural progression of DLS is known to be slower than that of other types of spinal deformity. Third, the definitive risk factors for deformity progression could not be found in the study. A risk factor analysis should have been conducted to determine the risk factors for the progression of PLI.

In conclusion, spine surgeons should be aware of the possibility of the progression of curvature after DL, which could be related to destabilization or aggravation of the natural progression. However, PLI was not always directly related to laminectomy.

\section{CONFLICT OF INTEREST}

No potential conflict of interest relevant to this article was reported.

\section{REFERENCES}

1. Nachemson A. Adult scoliosis and back pain. Spine (Phila Pa 1976). 1979;4(6):513-7.

2. San Martino A, D'Andria FM, San Martino C. The surgical treatment of nerve root compression caused by scoliosis of the lumbar spine. Spine (Phila Pa 1976). 1983;8(3):261-5.

3. Epstein JA, Epstein BS, Jones MD. Symptomatic lumbar scoliosis with degenerative changes in the elderly. Spine (Phila Pa 1976). 1979;4(6):542-7.

4. Shapiro GS, Taira G, Boachie-Adjei O. Results of surgical treatment of adult idiopathic scoliosis with low back pain and spinal stenosis: a study of long-term clinical radiographic outcomes. Spine (Phila Pa 1976). 2003;28(4):358-63.
5. Bridwell KH. Selection of instrumentation and fusion levels for scoliosis: where to start and where to stop: invited submission from the Joint Section Meeting on Disorders of the Spine and Peripheral Nerves, March 2004. J Neurosurg Spine. 2004;1(1):1-8.

6. Matsumura A, Namikawa T, Terai $\mathrm{H}$, et al. The influence of approach side on facet preservation in microscopic bilateral decompression via a unilateral approach for degenerative lumbar scoliosis. Clinical article. J Neurosurg Spine. 2010;13(6):758-65.

7. Benner B, Ehni G. Degenerative lumbar scoliosis. Spine (Phila Pa 1976). 1979;4(6):548-52. 
Ha et al. Post-Laminectomy Instability in Degenerative Lumbar Scoliosis

Clinics in Orthopedic Surgery • Vol. 12, No. 4, $2020 \bullet$ www.ecios.org

8. Kostuik JP. Recent advances in the treatment of painful adult scoliosis. Clin Orthop Relat Res. 1980;(147):238-52.

9. Transfeldt EE, Topp R, Mehbod AA, Winter RB. Surgical outcomes of decompression, decompression with limited fusion, and decompression with full curve fusion for degenerative scoliosis with radiculopathy. Spine (Phila Pa 1976). 2010;35(20):1872-5.

10. Seo JY, Ha KY, Hwang TH, Kim KW, Kim YH. Risk of progression of degenerative lumbar scoliosis. J Neurosurg Spine. 2011;15(5):558-66.

11. Kobayashi T, Atsuta Y, Takemitsu M, Matsuno T, Takeda N. A prospective study of de novo scoliosis in a community based cohort. Spine (Phila Pa 1976). 2006;31(2):178-82.

12. Schulitz KP. Risk of instability following decompression surgery for lumbar spinal stenosis. Z Orthop Ihre Grenzgeb. 1995;133(3):236-41.

13. Hansraj KK, Cammisa FP Jr, O'Leary PF, et al. Decompressive surgery for typical lumbar spinal stenosis. Clin Orthop
Relat Res. 2001;(384):10-7.

14. Vaccaro AR, Ball ST. Indications for instrumentation in degenerative lumbar spinal disorders. Orthopedics. 2000;23(3):260-71.

15. Yamada K, Matsuda H, Nabeta M, Habunaga H, Suzuki A, Nakamura H. Clinical outcomes of microscopic decompression for degenerative lumbar foraminal stenosis: a comparison between patients with and without degenerative lumbar scoliosis. Eur Spine J. 2011;20(6):947-53.

16. Simmons ED. Surgical treatment of patients with lumbar spinal stenosis with associated scoliosis. Clin Orthop Relat Res. 2001;(384):45-53.

17. Hopp E, Tsou PM. Postdecompression lumbar instability. Clin Orthop Relat Res. 1988;227:143-51.

18. Yasar B, Simsek S, Er U, et al. Functional and clinical evaluation for the surgical treatment of degenerative stenosis of the lumbar spinal canal. J Neurosurg Spine. 2009;11(3):34752. 